\title{
Neoextractivismo y conflictos ambientales en América Latina
}

\author{
Neoextractivismo and environmental \\ conflicts in Latin America
}

doi: http://dx.doi.org/10.32870/

espiral.v23i66.5300

\section{Resumen}

En este artículo se analiza cómo el común denominador de las economías latinoamericanas es la dependencia que tienen con la economía mundial como países productores de bienes primarios, a pesar de las diferencias estructurales económicas y políticas de los países latinoamericanos. Se utiliza el abordaje teórico y conceptual bautizado como modelo neoextractivista para explicar las características específicas que acarrea este y que conlleva en su matriz originaria acaparamiento de tierras y expulsión o desplazamiento de las comunidades rurales. Se concluye que el efecto de dicho modelo neoextractivista se traduce en una espiral de criminalización y represión de resistencias sociales por disputas territoriales en torno a una gran asimetría de poder.

Palabras clave: neoextractivismo, Estado, despojo, transnacionales, conflictos.

\author{
Marco Antonio Merchand Rojas
}

\begin{abstract}
The objective of this paper is to analyze how despite the economic and political structural differences of the Latin American countries, the common denominator of these economies is its dependence with the global economy as producers of primary goods. This exploitation of raw materials, called neoextractivista model, carries from its own origin hoarding of land, deportation or displacement of rural communities, establishing then, for natural consequences, a spiral of criminalization and repression of resistance by territorial disputes and divergent values around them, in a context of great power asymmetry.
\end{abstract}

Keywords: Neoextractivismo, State, dispossession, transnational, conflicts.

-Profesor-Investigador del Departamento de Sociedad y Economía del Centro Universitario del Sur (CUSUR), Universidad de Guadalajara. merchandrojas@yahoo.com.mx 


\section{Introducción}

El capitalismo globalizado territorial, a través de los sucesos de la historia (fordismo y posfordismo), ha construido una división internacional del trabajo y una división territorial de la producción mundial que determinan un rol fundamental para América Latina como proveedora de recursos naturales (agua, suelos, yacimientos minerales e hidrocarburos -recursos estratégicos-).

La apropiación de dichos recursos naturales (materias primas) se caracteriza por un coloniaje formal e informal que impone una lógica de acumulación a través los mecanismos de la compra, el alquiler o la concesión; estos mecanismos logran ser utilizados para dominar los recursos naturales (RN) gracias a dos protagonistas claves: el Estado-nación y el capital, que configuran espacios y lugares para la explotación de los RN.

Este nuevo paradigma de la actual geografía económica propicia una disputa global por los recursos naturales, siendo este suceso uno de los elementos más importantes de la dinámica del capitalismo contemporáneo para reproducir una lógica de acumulación sobre América Latina. Por la dimensión de las reservas de recursos estratégicos que posee América Latina, y por su condición histórica de ser una región exportadora de materias primas (commodities),${ }^{1}$ esta región tiene un alto grado de vulnerabilidad y dependencia de importaciones, no sólo de los Estados Unidos, sino, ahora, de la creciente demanda de China, que cobra auge como la mayor potencia comercializadora de commodities. Algunos analistas de la geopolítica ven en China una amenaza a la

I. Los commodities son un grupo específico de bienes que se comercializa mayoritariamente en el mercado internacional y que posee la característica particular de que los productos comerciados no se encuentran diferenciados entre sí (se los denomina, vulgarmente, "genéricos"). Por tal motivo, los precios pueden fijarse de forma transparente y ex ante en mercados específicos de alcance global.

\section{6}


hegemonía de Estados Unidos en el ámbito mundial, especialmente en el contexto de la crisis económica más reciente en Estados Unidos y Europa.

En la esfera económica, la reprimarización de las economías latinoamericanas está vinculada al incremento en la demanda de materias primas por el robusto crecimiento económico chino y su peso demográfico. Las empresas chinas han comenzado a invertir fuertemente en las industrias extractivas de América del Sur, y sus bienes manufacturados baratos compiten con los producidos en México y América Central.

En general, las economías latinoamericanas han ampliado su frontera extractiva, donde participan activamente las transnacionales. La ocupación de estos espacios locales o regionales por parte de estas empresas ha afectado profundamente los derechos y los territorios de los pueblos y comunidades indígenas. Así lo demuestran el Observatorio de Multinacionales de América Latina (OMAL, 2015) a través de su mapa interactivo, y los informes asociados a cada caso que ha elaborado la Coordinación por los Derechos de los Pueblos Indígenas.

\section{El estilo de desarrollo y el modelo neoextractivista}

El estilo de desarrollo y el modelo neoextractivista se corresponden con las propias estrategias macroeconómicas desplegadas por el Gobierno neoliberal que no sólo han sacrificado la economía real de los mexicanos, sino que también estas estrategias de estabilización, auspiciadas por el consenso de Washington, han sido la causa de la explotación de los recursos naturales y de la degradación ambiental de los países en desarrollo, como el caso de México, con un Estado-nación más que nunca dedicado a crear un clima de negocios benigno para la inversión extranjera que explota en forma indiscriminada los recursos naturales sólo con el fin 
de producir un excedente exportable, y que internaliza las externalidades negativas a cargo de los recursos naturales que sobreexplota.

Esta necesidad de los países en desarrollo de exportar bienes que socaban su patrimonio natural ahonda la deuda ecológica, que no es más que las exportaciones mal pagadas que realizan los países en desarrollado a los países desarrollados. Es claro que los precios de estas materias primas exportadas no incluyen diversos costos sociales y ambientales, propios de la explotación irracional que realizan las transnacionales de los países desarrollados. ${ }^{2}$

Como bien lo explican Martínez-Alier y Jusmet (2001), se propicia un comercio ecológicamente desigual que proviene de dos causas: en primer lugar, falta frecuentemente en el sur la fuerza necesaria para lograr incorporar las externalidades negativas locales en los precios de exportación; y, en segundo lugar, el tiempo natural necesario para producir los bienes exportados desde el sur es frecuentemente más largo que el tiempo necesario para producir los bienes y servicios importados, lo que provoca que en las economías del sur, o economías latinoamericanas, su crecimiento económico, con sus modalidades de la globalización de mercados bajo el esquema neoliberal, representa una seria amenaza para el medio ambiente e imposibilita su desarrollo sustentable.

Aquí se sostiene, al igual que lo hace Veltmeyer (2013), que se registra un impacto negativo del desarrollo de los recursos naturales en la tasa de intercambio en otros sectores -la llamada enfermedad holandesa, por ejemplo-, la volatilidad de los precios de las mercancías en el mercado

2. Se puede definir a la deuda ecológica como "aquella que ha venido siendo acumulada por el Norte, especialmente por los países más industrializados hacia las naciones del tercer mundo, a través de la expoliación de los recursos naturales por su venta subvaluada, la contaminación ambiental, la utilización gratuita de sus recursos genéticos o la libre ocupación de su espacio ambiental para el depósito de los gases de efecto invernadero u otros residuos acumulados y eliminados por los países industrializados" (Schatan, 1998, p. 18). 
mundial, la propensión hacia un ciclo de rápidos incrementos y rápida decadencia (boom-bust cycle), la susceptibilidad a la corrupción, la excesiva confianza en la inversión extranjera directa, la estructura de producción de enclave con escasas vinculaciones hacia adelante o hacia atrás con otros sectores de la economía, y una estructura social que inhibe el desarrollo más amplio de las fuerzas productivas de la sociedad y deriva en formas desiguales y exclusivas de crecimiento y en conflictos y guerras por los recursos.

De este modo, desde el estructuralismo latinoamericano y la escuela marxista de la dependencia hasta en los economistas neoclásicos y neoliberales, hay acuerdo en que la extracción de recursos ofrece una vía bastante difícil hacia el desarrollo. Sin embargo, los cambios en la economía mundial en años recientes han dado origen a la noción de que esta vez será diferente, que las modificadas condiciones del mercado mundial permitirían ahora que los países ricos en recursos exploten su ventaja comparativa en recursos naturales y se convierta en una bendición lo que alguna vez fue una maldición.

Los exponentes de esta perspectiva incluyen a varios economistas del Banco Mundial, quienes han publicado una serie de estudios que sugieren que el aumento reciente en la inversión extranjera a gran escala en tierra y en la extracción y explotación de los recursos naturales bajo las actuales condiciones tiene implicaciones positivas para muchos países en desarrollo, permitiéndoles aprovechar las nuevas oportunidades que ofrece una fuerte demanda de estos recursos en el mercado mundial (Banco Mundial, 2010 y 2011).

Por lo que respecta a las especificidades que cobra el neoextractivismo ${ }^{3}$ en los países emergentes, estas se refieren a aquellas actividades económicas que remueven grandes

3. El neoextractivismo está asociado a la existencia de enclaves, explotación laboral sin límite, violaciones a derechos humanos, el exterminio de grupos indígenas y la subordinación de los Gobiernos al poder de empresas multinacionales. Es un 
cantidades de recursos que no son procesados (o que lo son limitadamente) y que se destinan a la exportación. Sin embargo, esto no se limita a los minerales, gas o petróleo, sino que engloba materias primas agrarias, forestales e incluso productos pesqueros. Por ello, en la actualidad se plantea que los países de América Latina son exportadores de naturaleza.

La definición que le otorga una especificidad al neoextractivismo es la de la consolidación de un estilo de desarrollo definido como un patrón de acumulación basado en la sobreexplotación de recursos naturales, en gran parte no renovables, así como en la expansión de las fronteras hacia territorios antes considerados como improductivos. El neoextractivismo instala una dinámica vertical que irrumpe en los territorios y a su paso va desestructurando economías regionales, destruyendo biodiversidad, profundizando de modo peligroso el proceso de acaparamiento de tierras al expulsar o desplazar a comunidades rurales, campesinas o indígenas, y violentando procesos de decisión ciudadana (Gudynas, 2009).

El llamado "modelo extractivista" fue interrumpido por algunos pocos países latinoamericanos a partir de la crisis mundial de 1929 (Argentina, Brasil, México, Colombia, Perú, Chile y Uruguay), y estos iniciaron el camino hacia la industrialización dirigida por el Estado, o industrialización por sustitución de importación (ISI). Los países restantes no lograron superar las estructuras de exportaciones primarias. Sin embargo, se debe aclarar que las exportaciones primarias, si bien perdieron dinamismo, continuaron como principales fuentes de divisas, ya que los productos manufacturados se dirigían al mercado interno y eventualmente

callejón del que es difícil escapar. La estrategia de sustitución de importaciones aplicada entre 1940 y 1980 estaba diseñada para escapar de esta trampa, pero la crisis de la deuda de los años ochenta permitió imponer el régimen neoliberal, y el extractivismo regresó con ánimos de venganza. 
al regional. La participación de empresas transnacionales en el mercado local se benefició también del proteccionismo imperante en el mercado local.

Para la década de los años setenta del siglo pasado, la ISI ya no se sostenía, abatida por sus límites estructurales para poder llegar a otras etapas de industrialización más sofisticadas, con lo cual se puso fin al ciclo desarrollista y la regulación del Estado. Durante los años ochenta, el Fondo Monetario Internacional (FMI) y el Banco Mundial (BM) recomendaron a los países en desarrollo la aplicación de políticas de estabilización, primero, y ajuste estructural después.

Los programas de ajuste estructural (PAE) son la condición impuesta por el FMI y el BM a un país para otorgarle respaldo financiero destinado a afrontar un grave problema de pagos internacionales. Los PAE surgieron a comienzos de los años ochenta como respuesta a la crisis de la deuda externa de los países en desarrollo. Obedecen a una concepción extremadamente ortodoxa de la política económica, que años más tarde sería bautizada por sus propios impulsores como el consenso de Washington.

En efecto, desde los años setenta, y hasta el día de hoy, las economías de los países en desarrollo han estado dominadas por el enfoque neoclásico impuesto por los neoliberales, donde los operadores mundiales de tal modelo son los dos organismos financieros (FMI y BM) que sustentan el liderazgo de los Estados Unidos.

De igual manera, la teoría neoliberal se sustenta primordialmente en dos bases: primero, la defensa de la eficacia del mercado como mecanismo de asignación óptima de los recursos, junto con la crítica a la intervención pública en las actividades económicas en tanto generadora de distorsiones; segundo, la insistencia en las ventajas de una participación plena en el comercio internacional, junto con la crítica al modelo de industrialización por sustitución de 
importaciones, el cual muestra un claro sesgo antiexportador (Merchand, 2012).

A partir de las reformas impuestas por el consenso de Washington, se postuló que tendríamos que reaprovechar nuestras ventajas comparativas cifradas en productos cuya producción interna costara menos, así que se reivindicó por los neoliberales apostar de nuevo al modelo extractivista que nos ofrecía una mejor inserción al mercado mundial, sobre todo aprovechando un mercado más diversificado a partir de otros demandantes, como son los países asiáticos, fundamentalmente China, ávidos de invertir y comprar nuestras cotizadas materias primas. ${ }^{4}$

El Cuadro 1 refleja la importancia que tienen, sobre todo para los países sudamericanos, sus exportaciones de materias primas en el total de su producto interno bruto (PIB).

Como se ha sostenido, en las décadas de 1980 y 1990 se reafirmaron los programas de ajuste y estabilización, consistentes, entre otras cosas, en el acotamiento del papel del Estado (Merchand, 2012). Esto hizo que las empresas mineras o petroleras disfrutaran de un contexto de liberación de flujos de capital, acompañado de flexibilización o reducción de las regulaciones (laborales y ambientales, y de concesión de permisos para explotar nuestros recursos sin ninguna restricción).

\footnotetext{
4. Países asiáticos, y en especial China, se han convertido en compradores voraces de recursos naturales. Por ejemplo, el consumo chino de cobre fue de menos de I 000000 t en 1990, saltando a más de 6000000 en 2007, para lo cual debió importar más de 4500000 t. Cabe señalar que la extraordinaria expansión económica de China desde la década de 1990 se vio reforzada a partir de 2000 por los procesos de crecimiento de la India y otras economías emergentes. La demanda de hierro, cobre y aluminio, entre otros minerales de exportación, está asociada al crecimiento de los sectores de la construcción, la infraestructura y la manufactura (que requieren acero, conductores eléctricos y metales industriales, entre otros); estos sectores presentaron una rápida expansión en el marco del proceso de aceleración del desarrollo económico que han experimentado las grandes economías asiáticas. La rapidez del crecimiento económico de estas economías también ha contribuido a impulsar la demanda mundial de petróleo crudo y otros bienes primarios (UNASUR, 2013; Guydnas, 20I2).
} 
Cuadro 1. Exportaciones de productos primarios según su participación en el PIB

\begin{tabular}{lrrrrrrrrrrr}
\hline \multicolumn{1}{c}{ Porcentajes del valor total del PIB de las exportaciones FOB de bienes } \\
\hline \multicolumn{1}{c}{ País } & 2003 & 2004 & 2005 & 2006 & 2007 & 2008 & 2009 & 2010 & 2011 & 2012 & 2013 \\
\hline Argentina & 6.7 & 17.5 & 16.7 & 16.1 & 15.1 & 14.8 & 14.7 & 14.7 & 12.3 & 12.5 & 12.8 \\
Bolivia & 13.2 & 13.2 & 17.4 & 22.4 & 27.4 & 33.1 & 34.1 & 38.7 & 29.0 & 33.2 & 36.6 \\
Brasil & 4.9 & 5.7 & 6.4 & 6.8 & 6.3 & 6.2 & 6.1 & 6.6 & 5.8 & 6.0 & 6.8 \\
Chile & 22.4 & 21.5 & 22.8 & 26.6 & 26.8 & 32.2 & 34.1 & 33.8 & 25.5 & 27.9 & 29.0 \\
Colombia & 8.0 & 8.0 & 9.4 & 9.0 & 9.4 & 9.7 & 8.8 & 10.6 & 10.2 & 10.8 & 13.9 \\
Ecuador & 19.3 & 18.2 & 19.1 & 19.2 & 22.2 & 24.6 & 25.3 & 27.8 & 20.5 & 23.2 & 26.3 \\
Paraguay & 12.9 & 15.9 & 19.3 & 17.7 & 17.2 & 15.1 & 17.7 & 21.8 & 17.7 & 20.2 & 19.3 \\
Perú & 10.3 & 11.0 & 11.8 & 14.4 & 19.2 & 21.7 & 21.8 & 20.4 & 17.5 & 19.5 & 22.1 \\
Uruguay & 6.2 & 9.3 & 12.6 & 14.5 & 13.4 & 14.0 & 13.3 & 14.0 & 13.2 & 12.7 & $\ldots .$. \\
Venezuela & 18.3 & 22.3 & 26.1 & 26.0 & 32.0 & 26.7 & 23.0 & 27.3 & 15.8 & 25.4 & 27.1 \\
\hline
\end{tabular}

Fuente: CEPAL (2003 y 2013).

En el contexto señalado aquí, el Estado mínimo concede licencias o títulos para acceder a un recurso natural que corresponde a parte de la renta que se genera a través de una red de favores políticos-empresariales, renta que incluye regalías y tributos bajos a los capitales nacionales y extranjeros que apuesten por explotar los recursos mineros, energéticos y agrícolas (Gudynas, 2009, pp. 187-225). Aquí, las empresas transnacionales tienen un rol determinante; el Estado es funcional a esa transnacionalización que dinamiza sectores con ganancias extraordinarias.

Este neoextractivismo se caracteriza por mantener e incluso profundizar la extracción minera y petrolera, sea por un aumento de los rubros clásicos o por la incorporación de nuevos recursos (por ejemplo, países tradicionalmente no mineros que intentan la megaminería, como Uruguay, o países mineros que buscan nuevos rubros, como el litio en el caso de Bolivia). A su vez, el modo extractivista de organizar la producción se expande a otros sectores, en particular el de los monocultivos de exportación, como la soja en Argentina, Brasil y Paraguay. 
El Estado juega un papel mucho más activo que en el extractivismo clásico, sea por una participación directa por medio de empresas estatales, como la petrolera venezolana PDVSA, o por medios indirectos: asistencias financieras, subsidios, apoyos en infraestructura, etc. El empresario transnacional reaparece o cobra importancia bajo otros modos de asociación, tales como la migración o los contratos por servicios en el sector petrolero (joint-ventures) para la comercialización, como sucede en Bolivia.

Con el neoextractivismo, el Estado capta, o al menos intenta captar, mayores proporciones del excedente generado por los sectores extractivistas apelando a medidas como regalías o tributos más altos. A su vez, estos Gobiernos que apoyan y defienden estas prácticas sostienen que se permite recaudar más fondos, y que estos son utilizados en programas de lucha contra la pobreza. El hecho sustancial es que todos los Gobiernos progresistas ${ }^{5}$ defienden ese estilo, y uno de sus argumentos predilectos consiste en ligarlos a los planes contra la pobreza u otros tipos de programas en el campo de la justicia social; de esta manera ganan una legitimación social y política sustantiva.

Sin embargo, se genera un círculo vicioso, donde los planes contra la pobreza requieren de nuevos proyectos extractivistas, y estos a su vez generan nuevos impactos sociales y ambientales que requerirán de futuras compensaciones. De este modo, el Estado busca lograr delicados equilibrios entre sus concesiones al capital y la necesidad de regularlo, entre alentar el extractivismo y amortiguar sus impactos sociales y ambientales.

5. A partir de la década de los 2000 , gobiernos progresistas y de la llamada nueva izquierda accedieron al Gobierno en países de América como: Argentina (Néstor y Cristina Kirchner); Bolivia (Evo Morales); Brasil (Lula da Silva y Dilma Rouseff); Ecuador (Rafael Correa); Venezuela (Hugo Chávez, y hoy Nicolás Maduro); Chile (durante la etapa de Michelle Bachelet, y que puede repetirse con el nuevo mandato); Paraguay (Lugo); Perú (Ollanta Humala); y Uruguay (Tabaré Vázquez y José Mujica). 
El Cuadro 2 muestra la expansión del extractivismo en América del Sur.

Cuadro 2. Expansión del extractivismo en América del Sur desde inicios de los años 2000

\begin{tabular}{ll}
\hline Ecuador & El Gobierno aprobó el primer proyecto de megaminería a \\
& cielo abierto con una empresa china para extraer cobre. \\
& La reacción fue una gran marcha nacional ciudadana en \\
& defensa del agua y contra la megaminería. \\
Bolivia & Se buscó incentivar la explotación de gas y minerales, \\
& intentando sumar nuevos rubros como hierro o litio; las \\
& concesiones petroleras se extendieron a casi 12 000 000 ha. \\
Chile & Sigue arrastrando conflictos frente a la minería; actual- \\
& mente hay por lo menos dieciséis sitios sumidos en pro- \\
& blemas que van desde la contaminación del agua hasta la \\
& deforestación. \\
Colombia & El nuevo plan de gobierno consideró que la minería era una \\
& de las "locomotoras" del desarrollo, lo que provocó resisten- \\
& cias ciudadanas por sus impactos. \\
Brasil & Se ha convertido en el mayor país extractivista de Amé- \\
& rica Latina. Por ejemplo, en el 2011 se extrajeron más de \\
& 410 000 000 t de minerales, que en su mayor parte fueron \\
& exportados, alcanzando un récord de USD 50 000 000 000. \\
& Aunque no era un país minero, vive la insólita situación \\
& de un Gobierno que apoya el inicio de la megaminería de \\
hierro a cielo abierto, lo que ha desencadenado la protesta & de la sociedad civil. \\
Hruguay & Ha decidido profundizar la explotación minera, aprobando \\
& varias explotaciones, lo que ha desencadenado conflictos en \\
& por lo menos doce provincias.
\end{tabular}

Fuente: elaboración propia a partir de Gudynas (2009).

Este cuadro refleja ejemplos y tendencias de las inversiones llevadas a cabo por los Estados de América del Sur y, como bien lo explica Eduardo Gudynas (2012), la minería, hidrocarburos y monocultivos han recibido grandes inversiones y se han iniciado nuevos emprendimientos en casi todos los países. Se apela a prácticas cada vez más intensivas, a veces 
utilizando productos tóxicos y peligrosos, muchas veces usando explosivos, y se cubren áreas geográficas mayores, afectando por ejemplo las cuencas hidrográficas. Viejos emprendimientos son reactivados y profundizados, y países que no eran extractivistas ahora están comenzando a serlo.

Este extractivismo también es adjetivado por Svampa (2013), quien retoma las ideas planteadas en el libro compilado por Massuh (2012). La etiqueta empleada para este extractivismo es la de consenso de los commodities, que se define y caracteriza como el ingreso de América Latina en un nuevo orden económico y político-ideológico, sostenido por el boom de los precios internacionales de las materias primas y los bienes de consumo demandados cada vez más por los países centrales y las potencias emergentes.

Este orden va consolidando un estilo de desarrollo neoextractivista que genera ventajas comparativas, visibles en el crecimiento económico, al tiempo que produce nuevas asimetrías y conflictos sociales, económicos, ambientales y político-culturales. Tal conflictividad marca la apertura de un nuevo ciclo de luchas, centrado en la defensa del territorio y del ambiente, así como en la discusión sobre los modelos de desarrollo y las fronteras mismas de la democracia.

El concepto de commodities, en un sentido amplio, se entiende como productos indiferenciados cuyos precios se fijan internacionalmente, o como "productos de fabricación, disponibilidad y demanda mundial, que tienen un rango de precios internacionales y no requieren tecnología avanzada para su fabricación y procesamiento" (Svampa, 2013, p. 32). Ambas definiciones incluyen desde materias primas a granel hasta productos semielaborados o industriales. Para el caso de América Latina, la demanda de commodities está concentrada en productos alimentarios, como el maíz, la soja y el trigo, así como en hidrocarburos (gas y petróleo), metales y minerales (cobre, oro, plata, estaño, bauxita, zinc, entre otros). 
Cabe destacar que a partir de datos extraídos de Horacio Machado (2012) es interesante observar cómo, a escala mundial, la geografía de la extracción es muy diferente a la geografía del consumo. Por ejemplo, América Latina produce $26.2 \%$ de la bauxita en el mundo, pero sólo consume 2.9\%; en cuanto al cobre, produce $45.1 \%$ y consume $6.1 \%$; respecto al oro, produce $15.2 \%$ del total mundial y consume $3 \%$.

Esta demanda de commodities ha originado un importante proceso de reprimarización de las economías latinoamericanas al acentuar la reorientación de estas hacia actividades primarias extractivas o maquilas, con escaso valor agregado. Esta dinámica regresiva se ve agravada por el ingreso de potencias emergentes, como es el caso de China, ${ }^{6}$ país que de modo acelerado se va imponiendo como un socio desigual en lo que respecta al intercambio comercial con la región.

Si a este consenso de los commodities se le enfoca desde el punto de vista de la lógica de acumulación, conlleva la profundización de la dinámica de desposesión o despojo de tierras, recursos y territorios, y produce nuevas y peligrosas formas de dependencia y dominación. Entre los elementos comunes de esta dinámica podemos destacar la gran escala de los emprendimientos, la tendencia a la monoproducción o la escasa diversificación económica y una lógica de ocupación de los territorios claramente destructiva (Merchand, 2013).

Estas caracterizaciones generales sobre el neoextractivismo operan con la escala de los emprendimientos, que nos advierte también sobre la gran envergadura de las inversiones (se trata de actividades capital-intensivas y no trabajo-intensivas), así como sobre el carácter de los

6. En la actualidad, las exportaciones de América Latina hacia China se concentran sobre todo en productos agrícolas y minerales. "Así, para el año 2009 las exportaciones de cobre, hierro y soja representaban $55.7 \%$ de las exportaciones totales de la región al país oriental" (Merchand, 20I3, p. I2). 
actores involucrados y la concentración económica (grandes corporaciones transnacionales). En razón de ello, y de modo similar al pasado, este tipo de emprendimientos tiende a consolidar enclaves de exportación asociados a una lógica neocolonial que generan escasos encadenamientos productivos endógenos, operan una fuerte fragmentación social y regional, y van configurando espacios socioproductivos dependientes del mercado internacional.

Así, la megaminería a cielo abierto, la expansión de la frontera petrolera y energética (que incluye también la explotación de gas no convencional, o shale gas, con la tan cuestionada metodología del fracking), la construcción de grandes represas hidroeléctricas, la expansión de la frontera pesquera y forestal, la generalización del modelo de agronegocios (soja y biocombustibles), en fin, constituyen las figuras emblemáticas del neoextractivismo desarrollista.

Por último, pese a la tendencia a querer erigirse en discurso único, el consenso de los commodities ${ }^{7}$ aparece atravesado por una serie de ambivalencias, contradicciones y paradojas, ligadas de manera abierta a la enorme y creciente conflictividad socioambiental que la dinámica extractivista genera, así como también a los múltiples cruces existentes entre dinámica neoliberal, concepción del desarrollo, izquierdas y progresismo populista.

Los escenarios latinoamericanos más paradójicos del consenso de los commodities son los que presentan Bolivia

7. "Si durante la colonización española fue el trabajo esclavo o semiesclavo la fuente principal a partir de la cual se extraían y luego exportaban los recursos, a partir de la constitución de naciones latinoamericanas independientes fue, y sigue siendo, la contradicción principal entre capital y trabajo y el comercio desigual bajo condiciones de periferia y dependencia económica y política lo que determina los principios de la extracción-producción-exportación de los recursos. Es así que las naciones latinoamericanas se configuraron a lo largo de su historia como uno de los principales dadores de commodities al mundo industrializado. Recursos energéticos, biodiversidad y minería constituyen entonces los componentes fundamentales en la historia del desarrollo latinoamericano en tanto territorio complejo oferente de commodities" (Galafassi, 2012, s/p). 
y Ecuador. El tema no es menor, dado que ha sido en estos países donde, en el marco de fuertes procesos participativos, se han ido arreglando nuevos conceptos-horizontes como los de descolonización, Estado plurinacional, autonomías, buen vivir y derechos de la naturaleza.

Sin embargo, y más allá de la exaltación de la visión de los pueblos originarios en relación con la naturaleza (el buen vivir), inscripta en el plano constitucional, en el transcurrir del nuevo siglo, y con la consolidación de estos regímenes, otras cuestiones fueron tomando centralidad, vinculadas a la profundización de un neodesarrollismo extractivista. Incluso, como lo menciona Gabriela Massuh (2012) en su libro Renunciar al bien común. Extractivismo y (pos) desarrollo, el llamado giro a la izquierda acontecido en la última década en América Latina, si por un lado incorpora un discurso marcadamente antineoliberal, por otro continúa haciendo valer un modelo primario, extractivo y exportador, al servicio del interés capitalista, y con consecuencias nefastas para la región en términos ambientales, sociales y culturales, sobre las cuales resulta urgente actuar.

La siguiente cita textual, ilustra con claridad el párrafo anterior:

Este nuevo ciclo de "mineralización" de la América Latina se extiende ya a lo largo de la vasta diversidad biológica y climática de sus territorios, y abarca también los más diversos paisajes ideológicos de los Gobiernos vigentes. Hoy por hoy, el "consenso minero" unifica a todo el espectro variopinto de los oficialismos gobernantes: desde los Gobiernos de "derecha" (de la "moderada" y de la extrema), a los autoproclamados "progresistas" y hasta "revolucionarios"; desde aquellos que abren las puertas a la expansión del militarismo norteamericano, permiten la instalación de nuevas "bases" e impulsan los TLC con las potencias dominantes, a los que adoptan una retórica "antineoliberal", e incluso, a aquellos que modificaron sus constituciones y consagraron los "derechos de la naturaleza" y el "buen vivir". Al unísono con las grandes 
corporaciones del sector, los Gobiernos latinoamericanos defienden a rajatabla "la minería". El oficialismo prominero se ejerce instalando, día a día, a través de diferentes canales y lenguajes, el mensaje de que “sin minería no se puede vivir" (Machado, 2014, p. 12).

El común denominador de casi todos los Gobiernos latinoamericanos en términos de política económica, sean estos Estados progresistas o conservadores, es que todos se sometieron, como fue en su tiempo, al recetario hegemónico del neoliberalismo más voraz. El consenso de Washington, hoy en día, sigue persistiendo en América Latina, (re)articulado en lo que, en su ensayo, Svampa (2013) denomina consenso de los commodities, el cual responde, conforme a lo anterior, a un modelo que, igualmente integrado dentro del neoliberalismo, se sirve de la lógica extractiva sobre bienes naturales sin valor agregado, su alta rentabilidad para los actores económicos -que no para las comunidades locales-, su abundancia y su tendencia alcista tanto en los precios como en el consumo del mercado internacional.

Este llamado consenso de los commodities, también denominado por Eduardo Gudynas (2012) capitalismo benévolo, se erigiría, pues, desde un extractivismo transversal que afectaría igualmente a los recursos fósiles, a la producción de biocombustibles o al agronegocio de la soja y el maíz, llevando consigo consecuencias más que perjudiciales para la región. Algunas de ellas, aparte de una reprimarización de las economías latinoamericanas -por encima incluso de los niveles de la década de los ochenta-, serían la precarización del empleo rural, la conformación de una pérdida de soberanía alimentaria, la proliferación de prácticas de desposesión de tierra, además de elevadísimas dosis de fragmentación social y regional que, ahondando en las dinámicas socioproductivas del mercado internacional, habrían terminado por generar un escenario sumamente pernicioso para el medioambiente y los derechos humanos. 
Para seguir con la tónica de Gudynas, el Estado sudamericano se ajusta al estilo de desarrollo de talante extractivista y a la vez lo reproduce. El éxito actual de los Gobiernos, y en particular sus posturas optimistas frente a la crisis, sólo son posibles en la medida en que se mantenga el flujo de exportaciones de materias primas, sus altos precios y la atracción de inversiones. La caracterización que realiza Gudynas sobre el Estado es el rasgo común de los actuales Estados latinoamericanos, sean estos conservadores o progresistas.

El Estado libera y apoya dinámicas propias de una economía capitalista, permitiendo una intensa apropiación de la naturaleza, pero, por otro lado, intenta regular e intervenir esos ámbitos mercantiles. En efecto, todos los Gobiernos proclaman que su objetivo en el área económica es lograr crecimiento, lo que sería indispensable para generar empleo, captar renta para poder financiarse, etc. Por lo tanto, este Estado liberaliza y protege dinámicas propias del capitalismo contemporáneo, y se abstiene de intervenir cuando se ponen en riesgo esos procesos de acumulación. La promoción se hace con diferentes grados de apoyo y participación, que van desde cobertura jurídica hasta subsidios de diverso tipo, el aliento y protección al ingreso de inversiones, y hasta, en algunos casos, directamente el desarrollo de la actividad por medio de empresas nacionales.

Sin embargo, independiente de qué tipo de Estado se tiene (sesgo ideológico), este es un actor indispensable para asegurar las altas rentabilidades de una economía extractivista, como la minera, petrolera, forestal y de agronegocios, que tienen múltiples aspectos en común, como lo explican Norma Giarracca y Miguel Teubal:

Fueron impulsadas en el marco del neoliberalismo económico difundido a escala mundial; se vinculan con el interés de grandes corporaciones que las impulsan y que controlan sectores clave del espacio económico 
donde operan; se remiten a escalas de producción mucho mayores a las tradicionales y desplazan multiplicidad de actividades preexistentes; utilizan tecnologías de punta; se localizan territorialmente porque dependen de la existencia y la persistencia de determinados recursos naturales; desplazan masivamente tanto a trabajadores rurales como al campesinado, a la agroindustria en general y a pobladores cordilleranos circundantes; significan actividades con alto consumo de otros recursos no reproducibles, como el agua, la tierra fértil, la biodiversidad; se orientan fundamentalmente hacia las exportaciones, con lo cual no contribuyen a resolver necesidades internas; son altamente conflictivas respecto de las tradicionales actividades existentes en las distintas regiones (agricultura, ganadería, turismo, cultivos industriales); no son esenciales para la vida de las comunidades - o del mundo en general-. Estas actividades también son generadoras de grandes deseconomías externas, no consideradas por sus promotores (Giarracca y Teubal, 20I I, p. 9).

La especificidad de estas actividades extractivistas es que son impulsadas con gran ahínco por grandes empresas transnacionales que dominan sectores clave de la producción y tecnologías utilizadas en estos procesos. Como bien lo señala el OMAL, los Estados han ejercido un poder fáctico que ha impulsado, tanto como ha impuesto, la adopción de normas subordinadas a los principios neoliberales: las privatizaciones, las desregulaciones y el adelgazamiento del Estado de bienestar son reglas que preparan la pista de aterrizaje de las transnacionales para que estas exploten indiscriminadamente los recursos naturales.

\section{Explosión de conflictos socioambientales}

Necesariamente, hay que citar de nuevo a Svampa (2012) porque refleja muy bien lo acontecido con la instauración del modelo neoextractivista. Como más arriba se ha sostenido, desde el punto de vista de la lógica de acumulación, el nuevo consenso de los commodities conlleva la ampliación 
de la dinámica de desposesión o despojo de tierras, recursos y territorios, y produce nuevas y peligrosas formas de dependencia y dominación.

Entre los elementos comunes de esta dinámica podemos destacar la gran escala de los emprendimientos, la tendencia a la monoproducción o la escasa diversificación económica, y una lógica de ocupación de los territorios claramente destructiva. En efecto, en función de una mirada productivista y eficientista del desarrollo, se alienta la descalificación de otras lógicas de valorización de los territorios, que son considerados como socialmente vaciables, o lisa y llanamente como áreas de sacrificio, en aras del progreso selectivo (Merchand, 2013).

En otras palabras, el neoextractivismo instala una dinámica vertical que irrumpe en los territorios y a su paso va desestructurando economías regionales, destruyendo biodiversidad y profundizando de modo peligroso el proceso de acaparamiento de tierras al expulsar o desplazar a comunidades rurales, campesinas o indígenas, así como violentando procesos de decisión ciudadana.

Respecto a lo que se debe de entender por conflictos socioambientales, y estando al tono con lo explicado por Svampa (2008), los conflictos socioambientales son aquellos que están sujetados al acceso y control de los bienes naturales y el territorio, lo que supone, por parte de los actores enfrentados, intereses y valores divergentes en torno de ellos, en un contexto de gran asimetría de poder. Estos conflictos expresan diferentes concepciones sobre el territorio, la naturaleza y el ambiente, al tiempo que van estableciendo una disputa acerca de lo que se entiende por desarrollo y, de manera más general, por democracia. En la prevención en que los múltiples megaproyectos tienden a reconfigurar el territorio en su globalidad, no sólo se ponen en jaque las formas económicas y sociales existentes, sino también el alcance mismo de la democracia, pues esos proyectos se 
imponen sin el consenso de las poblaciones y generan de este modo fuertes divisiones en la sociedad y una espiral de criminalización y represión de las resistencias.

Sin embargo, es necesario encuadrar estos conflictos por la disputa de los recursos naturales en un marco conceptual que permita explicar las causas de dichos conflictos. Gian Carlo Delgado (2013), en la parte introductoria del libro Ecología política del extractivismo en América Latina: casos de resistencia y justicia socioambiental, presenta una semblanza de cómo dio origen al enfoque teórico de la ecología política, y sus aportes para estudiar el objeto de estudio.

Delgado (2013) comenta que la ecología política, como campo de estudio específico interesado en develar las causas y no meramente los síntomas, ha sido y es un proceso diverso, con énfasis heterogéneos y que da cuenta de la importancia que tienen en los análisis teórico-empíricos el reconocimiento explícito de los sistemas de poder, la influencia y la subordinación presentes en las relaciones sociales y productivas contemporáneas, en todas las escalas temporales y espaciales.

El susodicho autor agrega que el concepto como tal, de acuerdo a Robbins, ${ }^{8}$ fue probablemente utilizado por primera vez en 1972 por Wolf en su trabajo "Ownership and Political Ecology", en el que se introdujeron una serie de trabajos propios de la antropología y la ecología cultural para la zona andina, y en los que para Wolf se discuten transversalmente dos elementos clave: por un lado, el tema del acceso de cara a la propiedad de los recursos; y, por el otro lado, el de las dinámicas de la gestión de los territorios con visión de largo plazo, y de innegable naturaleza colectiva de frente a la propiedad privada de acciones individuales y a la gestión cortoplacista. 
Después, se tienen estudios más contemporáneos y acotados sobre el desarrollo extractivista y sus consecuencias sociales, económicas, y ecológicas. Destacan los trabajos de Martínez-Alier (1991 y 2003), Martínez-Alier y Jusmet (2001), Escobar (2010 y 2011), Toledo (1980, 1990, 1996 y 2003), Leff (1986 y 2006), y, por supuesto, los trabajos de Alimonda (2002 y 2006) y Quijano (1992, 2004 y 2007). Hay otros estudios más, pero estos son los que aportaron originariamente al debate ecológico-político, como sostiene Delgado (2013). Si bien estos textos no necesariamente son típicos de la diversidad y complejidad de la ecología política de los recursos naturales del continente, son, sin lugar a dudas, contribuyentes apreciables al debate actual.

El Cuadro 3 indica algunos casos que registran los conflictos ambientales en América Latina. Por la cantidad de estos conflictos no hay espacio para hablar de su problemática específica; simplemente se enumeran por subsector.

Cuadro 3. Casos de conflictos ambientales en América Latina

\begin{tabular}{|c|c|c|c|}
\hline $\begin{array}{l}\text { Sub- } \\
\text { sector }\end{array}$ & País & Recurso natural & $\begin{array}{l}\text { Número } \\
\text { de casos }\end{array}$ \\
\hline \multirow{11}{*}{ 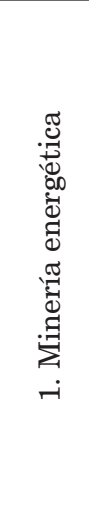 } & Argentina & Gas, carbón, petróleo y uranio & 5 \\
\hline & Belice & Petróleo & 1 \\
\hline & Bolivia & Petróleo & 1 \\
\hline & Brasil & $\begin{array}{l}\text { Fosfato, uranio, complejo } \\
\text { petroquímico, carbón }\end{array}$ & 4 \\
\hline & Chile & Carbón & 1 \\
\hline & Colombia & Carbón & 2 \\
\hline & Costa Rica & Petróleo y gas & 1 \\
\hline & Ecuador & Petróleo & 4 \\
\hline & Guatemala & Petróleo & 1 \\
\hline & Guyana Francesa & Petróleo & 1 \\
\hline & México & Gasoducto y carbón & 2 \\
\hline
\end{tabular}




\begin{tabular}{|c|c|c|c|}
\hline $\begin{array}{l}\text { Sub- } \\
\text { sector }\end{array}$ & País & Recurso natural & $\begin{array}{l}\text { Número } \\
\text { de casos }\end{array}$ \\
\hline \multirow{5}{*}{ 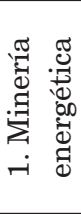 } & Panamá & Petróleo & 1 \\
\hline & Perú & Gas natural y petróleo & 2 \\
\hline & Puerto Rico & Gasoducto & 1 \\
\hline & Venezuela & Petróleo y gas metano & 5 \\
\hline & & & ubtotal: 32 \\
\hline \multirow{19}{*}{ 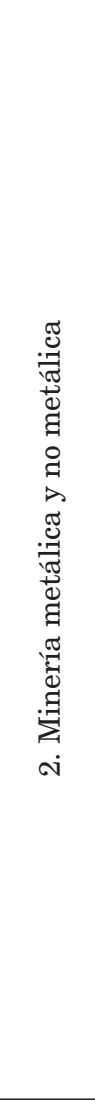 } & Argentina & $\begin{array}{l}\text { Oro, plata, cobre, polimetales, metal } \\
\text { doré, cloruro de potacio, plomo, litio, } \\
\text { molibdeno }\end{array}$ & 14 \\
\hline & Bolivia & $\begin{array}{l}\text { Zinc, plomo, plata, diversos } \\
\text { materiales, indio, iridio }\end{array}$ & 3 \\
\hline & Brasil & $\begin{array}{l}\text { Níquel, hierro, polo siderúrgico, } \\
\text { zinc, oro y bauxita }\end{array}$ & 8 \\
\hline & Chile & Oro, cobre, doré y mineroducto & 4 \\
\hline & Colombia & Níquel, oro, plata, cobre, molibdeno & 5 \\
\hline & Costa Rica & Oro & 2 \\
\hline & Ecuador & Cobre, oro y plata & 5 \\
\hline & El Salvador & $\begin{array}{l}\text { Oro, plata, cemento, níquel, } \\
\text { ferroníquel }\end{array}$ & 7 \\
\hline & Honduras & Oro & 2 \\
\hline & México & Oro, plata, zinc, barita, plomo & 12 \\
\hline & Nicaragua & Metales pesados, oro y plata & 2 \\
\hline & Panamá & $\begin{array}{l}\text { Oro, minería metálica, piedra de } \\
\text { cantera }\end{array}$ & 5 \\
\hline & Paraguay & Aluminio, oro & 2 \\
\hline & Perú & $\begin{array}{l}\text { Cobre, molibdeno, complejo } \\
\text { polimetálico, oro }\end{array}$ & 7 \\
\hline & República & Níquel, oro & 2 \\
\hline & Dominicana & & \\
\hline & Uruguay & Hierro & 1 \\
\hline & Venezuela & Oro, níquel & 3 \\
\hline & & & ubtotal: 82 \\
\hline \multirow{4}{*}{$\begin{array}{l}\frac{\pi}{2} \\
\stackrel{200}{4} \\
\infty\end{array}$} & Argentina & Aguas superficiales, represa & 5 \\
\hline & & hidroeléctrica, represa, dique & \\
\hline & Bolivia & $\begin{array}{l}\text { Extracción de agua subterránea, } \\
\text { contaminación de aguas por minería }\end{array}$ & 2 \\
\hline & Brasil & Presas & 6 \\
\hline
\end{tabular}




\begin{tabular}{|c|c|c|c|}
\hline $\begin{array}{l}\text { Sub- } \\
\text { sector }\end{array}$ & País & Recurso natural & $\begin{array}{l}\text { Número } \\
\text { de casos }\end{array}$ \\
\hline \multirow{10}{*}{ 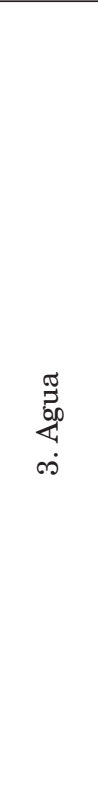 } & Chile & $\begin{array}{l}\text { Central hidroeléctrica, } \\
\text { termoeléctrica, complot } \\
\text { hidroeléctrico, contaminación de } \\
\text { agua }\end{array}$ & 5 \\
\hline & Colombia & $\begin{array}{l}\text { Desviación de río, hidroeléctrica, } \\
\text { represa, proyecto hidroeléctrico }\end{array}$ & 5 \\
\hline & Costa Rica & Hidroeléctrica, represa & 1 \\
\hline & Ecuador & Represa, hidroeléctrica & 3 \\
\hline & El Salvador & $\begin{array}{l}\text { Manglar, presas hidroeléctricas, } \\
\text { contaminación de agua }\end{array}$ & 3 \\
\hline & Guatemala & Proyecto hidroeléctrico & 1 \\
\hline & México & $\begin{array}{l}\text { Presa hidroeléctrica, proyecto } \\
\text { hidráulico, aguas superficiales y } \\
\text { subterráneas, acueducto, presa }\end{array}$ & 6 \\
\hline & Panamá & $\begin{array}{l}\text { Hidroeléctrica, diversos proyectos } \\
\text { hídricos }\end{array}$ & 2 \\
\hline & Perú & Hidroeléctrica & 1 \\
\hline & $\begin{array}{l}\text { República } \\
\text { Dominicana }\end{array}$ & Abastecimiento de agua potable & 1 \\
\hline
\end{tabular}

Subtotal: 39

\begin{tabular}{|c|c|c|c|}
\hline \multirow{9}{*}{ 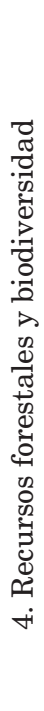 } & Argentina & Bosques & 1 \\
\hline & Brasil & $\begin{array}{l}\text { Deforestación: madereros ilegales, } \\
\text { extracción de caucho, empresa de } \\
\text { eucalipto }\end{array}$ & 3 \\
\hline & Chile & $\begin{array}{l}\text { Pino, eucalipto, sustitución de } \\
\text { bosque nativo por plantaciones } \\
\text { forestales, recursos forestales }\end{array}$ & 3 \\
\hline & Colombia & Madera & 1 \\
\hline & Ecuador & Madereras & 1 \\
\hline & Haití & Reforestación & 1 \\
\hline & México & $\begin{array}{l}\text { Manglar, tala clandestina, tala de } \\
\text { bosques }\end{array}$ & 3 \\
\hline & Paraguay & Desalojo de reserva forestal & 1 \\
\hline & Venezuela & $\begin{array}{l}\text { Explotación de reserva forestal por } \\
\text { madera y recursos mineros. Tendido } \\
\text { eléctrico en bosques y parques } \\
\text { nacionales }\end{array}$ & 2 \\
\hline
\end{tabular}




\begin{tabular}{|c|c|c|c|}
\hline $\begin{array}{l}\text { Sub- } \\
\text { sector }\end{array}$ & País & Recurso natural & $\begin{array}{l}\text { Número } \\
\text { de casos }\end{array}$ \\
\hline \multirow{11}{*}{ 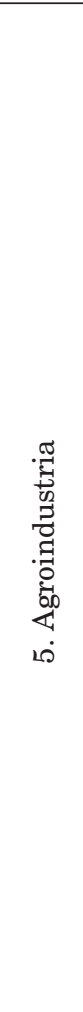 } & Argentina & Soya, cultivos de soya & 2 \\
\hline & Bolivia & Cultivos de caña & 1 \\
\hline & Brasil & $\begin{array}{l}\text { Monocultivo de eucalipto y } \\
\text { agroindustria de soja, uso } \\
\text { de plaguicidas, ganadería, } \\
\text { agrocombustibles }\end{array}$ & 4 \\
\hline & Chile & $\begin{array}{l}\text { Transgénicos, crianza de cerdos } \\
\text { para industria agroalimentaria, } \\
\text { uso y producción de agroquímicos, } \\
\text { residuos generados por la planta de } \\
\text { celulosa }\end{array}$ & 5 \\
\hline & Colombia & $\begin{array}{l}\text { Cultivo de palma de aceite para } \\
\text { agrocombustibles, semillas criollas, } \\
\text { palma africana }\end{array}$ & 3 \\
\hline & Ecuador & Monocultivo de palma africana & 2 \\
\hline & Haití & Semillas de Monsanto & 1 \\
\hline & México & $\begin{array}{l}\text { Soya transgénica, maíz transgénico, } \\
\text { ganado porcino }\end{array}$ & 3 \\
\hline & Paraguay & $\begin{array}{l}\text { Maíz transgénico, algodón } \\
\text { transgénico, monocultivo de soja, } \\
\text { ganadería ilegal }\end{array}$ & 6 \\
\hline & Perú & Palma aceitera & 1 \\
\hline & Uruguay & $\begin{array}{l}\text { Planta de celulosa, contaminación } \\
\text { del río Uruguay }\end{array}$ & 1 \\
\hline
\end{tabular}

Subtotal: 28

Total: 197

Por supuesto que este cuadro es una aproximación de los casos de explotación de recursos naturales y los conflictos que se provocan. Por ejemplo, se reporta en 2016 que "el Gobierno boliviano acaba de conceder a la empresa china Sinosteel la construcción de una planta para procesar el hierro del Mutún, uno de los yacimientos más importantes de Sudamérica, cerca de la frontera entre Bolivia y Brasil. Con ello, Bolivia comenzará su propia industria siderúrgica, una constante aspiración del presidente Evo Morales. La operación costará algo menos de USD 400000000 y confirma el predominio en Bolivia de los proveedores y socios de China" (Molina, 2016).

Fuente: elaboración propia a partir de Delgado (2013). 
Este cuadro refleja los conflictos socioambientales y cómo estos se han convertido, de manera creciente, en denominador común de planes y políticas de desarrollo y conservación en América Latina. ${ }^{9}$ Las tendencias y proyecciones para el corto y mediano plazo indican que estos conflictos irán en sostenido aumento, tomando en consideración el uso exponencial al cual están sometidos los recursos naturales en la región, así como a escala planetaria. Casi sin excepción, se trata de conflictos que involucran a una gran diversidad de actores en disputa por el uso de los mencionados recursos, donde se ven confrontados actores del Estado, comunidades y organizaciones locales, pueblos indígenas, empresas nacionales o corporaciones transnacionales, y organizaciones no gubernamentales nacionales e internacionales. Si bien los conflictos socioambientales pueden potencialmente causar un deterioro irreparable de los recursos naturales, así como sobre las relaciones entre instituciones, empresas y grupos sociales, pueden también potenciar procesos de transformación.

La intensificación de la extracción de los recursos naturales en las últimas décadas ha ampliado las fronteras donde las empresas transnacionales explotan minerales, hidrocarburos, bosques, ríos, etc., ocasionando crecientes conflictos socioambientales. Un caso representativo de los conflictos entre las empresas extractivas y los pueblos amazónicos por la propiedad y el uso del territorio es lo ocurrido en la provincia de Condorcanqui, en la cordillera del Cóndor, cerca la frontera de Perú con Ecuador. En esta zona, Minera Afrodita, subsidiaria de la compañía canadiense Dorato Resources, obtuvo unas 5100 ha de concesión para la exploración minera con miras a extraer oro, cobre

9. Sólo en Perú, los conflictos socioambientales habían aumentado de veintitrés, en 2007, a ciento cuarenta y nueve, en septiembre de 2012; es decir, representaban más del 60\% del total (Sanborn y Dammert, 20I3). 
y uranio. Los pueblos awajum y wampis, ancestralmente asentados en esta zona, se han opuesto sistemáticamente y por diversas vías a las actividades mineras, pues consideran que contaminarán con mercurio y cianuro los ríos Cenepa y Marañón y alterarán el ecosistema en su conjunto. El malestar provocado por el avance de la minería, pese a las reiteradas solicitudes de las organizaciones indígenas sustentando su oposición, llevó a que los nativos awajum retuvieran a cinco trabajadores de la empresa para exigir al Estado que intervenga y regule las actividades contaminantes en una zona que ya había sido considerada reserva ecológica (Durand, 2011).

Sin embargo, acorde con la base de datos de conflictos mineros del Observatorio de Conflictos Ambientales (OLCA) ${ }^{10}$ y la Coordinación Ejecutiva del Observatorio de Conflictos Mineros en América latina (OCMAL), se registraban -hasta 2013- un total de doscientos cuatro conflictos en diecinueve países de la región (seis de ellos son de carácter transfronterizo), los cuales afectaban a doscientas noventa y siete comunidades. En el mapa de la base de datos señalada se observa el número de conflictos mineros (ver, también: Hazin -2013-). La minería no es cualquier actividad, sino aquella que ostenta el mayor grado de militarización del modelo extractivo. Perú es, junto con México y Chile, el país que concentra más conflictos mineros, según el OCMAL. Entre los grandes países de la región, los mencionados son los tres donde el militarismo ha convertido a las comunidades indias, negras y mestizas, rurales y urbanas, en campos donde se impone el estado de excepción permanente.

Cabe aquí hacerse los planteamientos de Massuh (2012), quien dice que violencia, despojo y capitalismo contienen aquí, con toda su crudeza, su referencia primigenia. Ahora

10. Observatorio de Conflictos por los Recursos Naturales (OCRN). Para más información, ver: http://www.avina.net/esp/I 0427/incontext-32/\#sthash.rQiTIOfa. dpufhttp://ocrn.info/ 
bien, ¿todo proceso de desarrollo supone esta tríada? ¿La modernidad es apenas esto? ¿Nos referimos a fenómenos semejantes cuando describimos el capital, la modernidad y el desarrollo?

Lo cierto es que, en el caso de conflictos provocados por el extractivismo, se genera una perspectiva que plantea la importancia de los dirigentes comunitarios para la resistencia. Por ello, se han descrito casos de muertes y asesinatos a líderes locales y de movimientos por la defensa de los territorios y los recursos naturales. En otras palabras, el escenario descrito da cuenta del avance de un modelo neoliberal de mercado que en Latinoamérica significó la instalación de un neoextractivismo actual, sustentado en un colonialismo interno y transnacionalizado que ha propiciado la emergencia de conflictos.

Como sostienen Correa y Rodríguez (2005), hoy más que nunca los conflictos socioambientales son una parte central de los procesos de desarrollo y de rearticulación de América Latina en las agendas globales, así como de la práctica de políticas públicas y de la gestión y administración del territorio y los recursos naturales. Estos conflictos se caracterizan por su complejidad, variedad temática y por la gran diversidad de actores involucrados. Entre los temas resaltantes, destacan los problemas de contaminación y deforestación, los impactos de megaproyectos como la minería y la explotación hidroeléctrica, el acceso y uso de áreas protegidas, la planificación y ordenación de zonas urbano-rurales, el acceso a la tierra, la posesión de territorios tradicionales, y el manejo de recursos pesqueros. Casi sin excepción, se trata de conflictos que involucran desde actores del Estado, comunidades y organizaciones locales, pueblos indígenas, empresas nacionales o corporaciones transnacionales, hasta organizaciones no gubernamentales y académicas. La raíz común de la mayor parte de estos conflictos es el incremento de la competencia por el acceso 
y uso de los recursos naturales en nuestra región y en el mundo en general.

Regresando de nuevo al argumento central del trabajo, según lo explicado por Composto y Navarro (2011), desde su génesis, la historia del capitalismo ha estado atravesada por el ejercicio permanente del despojo sobre la naturaleza, los seres humanos y sus mundos de vida. Efectivamente, el capitalismo es un sistema global que responde a una dinámica de expansión constante, tanto en términos productivos como geográficos, guiada por un único principio rector: la acumulación incesante (Wallerstein, 2008). Para ello, necesita separar a los hombres de sus medios de producción y reproducción de la vida, a fin de convertirlos en fuerza de trabajo "libre" -desposeída-y susceptible de ser explotada.

En otras palabras, necesita transformar a la naturaleza en un mero medio de producción, y a todos los procesos vivos que le son inherentes en potenciales mercancías, y destruir todas aquellas relaciones sociales, constelaciones culturales y lenguajes de valoración propios de otras matrices civilizatorias para subsumirlas a la lógica unidimensional del mercado (el tiempo abstracto, el individualismo y la ganancia privada). La violencia y el despojo constituyen la condición y signo del origen neoextractivista.

De modo que la violencia y el despojo son los pilares fundacionales del andamiaje capitalista, pero de ninguna manera pueden reducirse a un conjunto de acontecimientos explicativos del pasado, ya que han mantenido un rol continuo y persistente en la amplia geografía histórica de la acumulación de capital hasta nuestros días. En definitiva, los procesos de desposesión son constitutivos e intrínsecos a la lógica de la acumulación del capital, o en otras palabras, representan la contracara necesaria de la reproducción ampliada. Si esta última se presenta como un proceso principalmente económico, que cobra preeminencia durante los periodos de estabilidad y crecimiento sostenido, el despojo 
se expresa generalmente en procesos extraeconómicos de tipo predatorio y toma las riendas en momentos de crisis, a modo de solución espacio-temporal o huida hacia adelante.

También habría que agregar otra forma de análisis, la que expone Machado (2009, 2010 y 2012): los procesos de expropiación ecológica tienen profundas consecuencias económicas y políticas; implican inexorablemente que lo que unos consumen es lo que a otros les es quitado. El agua y la energía que consumen las mineras en los territorios de nuestra región, por ejemplo, es agua y energía que es negada y expropiada a las propias poblaciones locales.

\section{Conclusiones}

Se ha analizado cómo los Gobiernos de América Latina justifican un estilo de desarrollo extractivista que genera círculos viciosos no sólo en la población (explotación desmedida, bajos salarios, no se cuenta con prestaciones labores -seguro médico, ahorros, etc.-), sino también en el entorno territorial de estas poblaciones: al estar sometido a una sobrecarga de sus recursos naturales, se tiene como resultado depredación y degradación de su medio ambiente.

Esta paradoja perversa del sistema es propia de la lógica que opera en los Gobiernos en comparsa con las empresas para mantener un sistema productivo con altos rendimientos para una clase empresarial nacional y extranjera. Sin embargo, estas empresas productivas que comercializan exitosamente sus productos en el exterior, aprovechando sus "ventajas comparativas", no generan para sus trabajadores una vida digna y decorosa.

Las comunidades originarias y dueñas de sus recursos (tierra, agua) son despojadas arbitrariamente de sus medios de subsistencia. Estas poblaciones inertes e indefensas luchan por que se les restituya lo que les pertenece. Esto genera creciente conflictividad socioambiental entre los 
actores involucrados (Estado, empresas y trabajadores). No obstante que han crecido los conflictos por disputas y conquistas de territorios entre los involucrados, el Estado sigue manteniendo una política de defensa a favor de los intereses empresariales que socaban y depredan la biodiversidad de los territorios ocupados, destruyendo por consecuencia el tejido productivo social y cultural de sus pobladores originarios.

Habría que agregar, también, que el negocio lucrativo sobre el aprovechamiento de los recursos naturales se expresa en un neoextractivismo que constituye un escenario favorable para una próspera clase rentista (empresas nacionales, transnacionales y operadores de Gobierno) que acumula más y más riqueza y poder y es situada privilegiadamente en un sistema económico-político exclusivo y explotador de fuerza de trabajo y recursos naturales. El dominio que ejerce la clase rentista (por ejemplo, los titulares de los derechos de propiedad minera, agrícola, petrolera) sobre los denominados activos y recursos "naturales" le permite crear y manipular la escasez, así como especular con el valor de los activos que controla.

Esta clase rentista ejerce el derecho del "acaparamiento de tierras" que se está llevando a cabo actualmente en todo el mundo (América Latina, África), y que tiene que ver más con la creciente competencia por monopolizar los recursos y la cadena alimentaria con vistas a la extracción de rentas que con el temor a unos inminentes límites naturales impuestos a la producción de alimentos y la extracción de minerales.

También es a través del comercio internacional de materias primas que existe una transferencia real o virtual de insumos (agua, energía, minerales, biomasa y nutrientes, así como los efectos del trabajo humano) de una parte a otra del planeta. Este comercio es el adhesivo que mantiene unido el sistema capitalista, y es su expansión la 
que extiende e intensifica las actividades que tienen lugar dentro del mismo. En este sentido, la categoría de transferencia ecológica se ejemplifica en el caso de la explotación de petróleo crudo de México, que se exporta a Estados Unidos y que este regresa procesado como gasolina o gas.

El sistema capitalista está plagado de desigualdades y desarrollos geográficos irregulares, precisamente como consecuencia del patrón desigual de estas transferencias. Los beneficios se amontonan en una parte del mundo a costa de la otra. Un claro ejemplo de esto es lo que ha acontecido con América Latina en cuestión de transferencia de los beneficios ecológicos a partir de la explotación de su naturaleza y recursos naturales. Hay que recordar que el capital ha agotado, e incluso destruido, de forma irreparable los recursos latentes en la naturaleza de ciertos lugares (ejemplos como el gaucho, el henequén, etc.). Las colonias y las neocolonias fueron explotadas y son explotadas por sus recursos, sin importar el bienestar de las poblaciones locales (a menudo indígenas).

La extracción de minerales y la explotación de los recursos energéticos y forestales suelen seguir una lógica similar, dejando tras de sí un paisaje desigual de ciudades mineras abandonadas, suelos agotados, vertederos de residuos tóxicos y valores de activos devaluados. Estas prácticas extractivas y explotadoras se tornan doblemente voraces y violentas bajo regímenes imperiales y coloniales. Los beneficios y las pérdidas desiguales casi siempre redundan, sin embargo, en beneficio de los ricos y los poderosos, dejando a los vulnerables y a los pobres mucho peor de lo que estaban. Esto es, al fin y al cabo, en lo que siempre ha consistido el imperialismo extractivo.

La explotación de la tierra, la erosión del suelo y la extracción incontrolada de los recursos naturales han dejado una huella de enormes proporciones en los paisajes de todo el mundo, y en algunos casos han provocado la destrucción 
irreversible de aquellos valores de uso necesarios para la supervivencia humana. Sin embargo, el capital no puede menos que privatizar, mercantilizar, monetizar y comercializar todos aquellos aspectos de la naturaleza a los que tiene acceso. Sólo así le es posible absorberla cada vez más intensamente de modo que se convierta en una forma de capital, esto es, en una estrategia de acumulación. La colonización de nuestro mundo de vida por el capital se acelera. La infinita y cada vez más absurda acumulación exponencial de capital se ve acompañada de una infinita y cada vez más absurda invasión del mundo de vida por la ecología del capital.

Como se analizó, se instaura un proceso que se denomina "ofensiva extractivista", con acelerado avance expropiatorio, mercantilista y depredador de los bienes comunes naturales de la región. El agronegocio, la minería a gran escala, la explotación de hidrocarburos no convencionales, la industria forestal y la construcción de megaproyectos de infraestructura (carreteras, gasoductos, termoeléctricas, represas, etc.) son actividades únicas de esta nueva ola de saqueo, dependencia y recolonización a la que están sujetos los países de América Latina. Se puede decir que casi todos los estudios académicos recientes coinciden en las que las actividades de extracción de minerales o hidrocarburos generan situaciones de pobreza y de autoritarismo, y que se propician relaciones entre unas y otras.

Fecha de recepción: 08 de mayo de 2015

Fecha de aceptación: 19 de febrero de 2016

Bibliografía

\section{6}


(coord.), La naturaleza colonizada. Ecología política y mineBibliografía ría en América Latina (pp. I I-303). Buenos Aires: CLACSO. Banco Mundial (2010). Rising Global Interest in Farmland: Can it Yield Sustainable and Equitable Benefits? Washington: World Bank.

(20I I). The World Bank Group in Extractive Industries. 20I I Annual Review. Washington: World Bank.

CEPAL (2003). Anuario estadístico de América Latina y el Caribe. Santiago de Chile: Comisión Económica para América Latina y el Caribe.

(20I3). Anuario estadístico de América Latina y el Caribe. Santiago de Chile: Comisión Económica para América Latina y el Caribe.

Chomsky, N. (2005). Ambiciones imperiales. Barcelona: Ediciones Península.

Composto, C., y Navarro, L. (20I I). Estados transnacionales extractivos y comunidades movilizadas: dominación y resistencias en torno de la megaminería en América Latina. VI Jornadas de Jóvenes Investigadores. Buenos Aires: Instituto de Investigaciones Gino Germani.

Correa, H., y Rodríguez, I. (2005). Encrucijadas ambientales en América Latina. Entre el manejo y la transformación de conflictos por recursos naturales. Costa Rica: Programa C y C Universidad para la Paz.

Delgado, C. (2013). Ecología política del extractivismo en América Latina: casos de resistencia y justicia socioambiental. Buenos Aires: CLACSO.

Durand, A. (20II). ¿Tierras de nadie? Actividad extractiva, territorio y conflicto social en la Amazonía peruana: el río Cenepa. Lima: Asociación Servicios Educativos Rurales y Coalición Internacional para el Acceso a la Tierra. Recuperado de: http://www.landcoalition.org/sites/default/ files/publication/I026/CENEPA_ESP_web_16.03.II.pdf Escobar, A. (2010). "Ecologías políticas postconstructivistas". Revista Sustentabiliad(es), (2). Recuperado de: www. 
sustentabilidades.org/revista/publicacion-02/ecologiaspoliticaspostconstructivistas

(20I I). "Ecología Política de la globalidad y la diferencia", en $\mathrm{H}$. Alimonda (comp.), La naturaleza colonizada. Ecología política y minería en América Latina (pp. 6I-93). Buenos Aires: CLACSO.

Galafassi, G. (20I2). "¿Qué hay de nuevo, viejo? Procesos de movilización y conflictos socio-ambientales". Conflicto social, 5(8). Recuperado de: https://www.academia. edu/963367I/Galafassi_Qu\%C3\%A9_hay_de_nuevo_ viejo_Procesos_de_movilizaci\%C3\%B3n_y_conflictos_socio-ambientales

Giarracca, N., y Hadad, G. (2009). “Disputas manifiestas y latentes en La Rioja minera. Política de vida y agua en el centro de la escena”, en M. Svampa (ed.), Minería trasnacional, narrativas del desarrollo y resistencias sociales (pp. 229-25I). Buenos Aires: Biblos.

$\longrightarrow$ y Teubal, M. (20II). Disputas por los territorios y recursos naturales: el modelo extractivo. Recuperado de: http://www.alasru.org/wp-content/uploads/20I I/06/ Giarraca-y-Teubal.pdf

Gudynas, E. (2009). "Diez tesis urgentes sobre el nuevo extractivismo en Extractivismo y sociedad", en F. Rhon Dávila, J. Schuldt, A. Acosta, et al. (auts.), Extractivismo, política y sociedad (Pp. 187-225). Quito: CAAP (Centro Andino de Acción Popular) y CLAES (Centro Latino Americano de Ecología Social). Recuperado de: http:// www.gudynas.com/publicaciones/GudynasNuevoExtractivismol0Tesis09×2.pdf

(20I2). "Estado compensador y nuevos extractivismos. Las ambivalencias del progresismo sudamericano". Nueva sociedad, (237). Recuperado de: http://nuso.org/ articulo/estado-compensador-y-nuevos-extractivismoslas-ambivalencias-del-progresismo-sudamericano/ 
(20I2). Hay alternativas al extractivismo. Transiciones

Bibliografía para salir del viejo desarrollo. Perú: Centro Peruano de Estudios Sociales-CEPES. Recuperado de: http://therightsofnature.org/wp-content/uploads/pdfs/Espanol/ Gudynas_Post-extractivismo_20I2.pdf

Hazin, M. (20I3). Desarrollo minero y conflictos socioambientales. Santiago de Chile: CEPAL. Recuperado de: http:// repositorio.cepal.org/bitstream/handle/I I362/5369/ LCL3706_es.pdf?sequence= I

Jalife-Rahme, A. (20I5). “ ¿Sustituye China a EU como superpotencia global?”. La Jornada. Recuperado de: http:// www.jornada.unam.mx/2015/04/22/opinion/016olpol

Leff, E. (1986). Ecología y capital. Racionalidad ambiental, democracia participativa y desarrollo sustentable. México: Siglo XXI/UNAM.

(2006). "La ecología política en América Latina. Un campo en construcción” en $\mathrm{H}$. Alimonda (coord.), Los tormentos de la materia. Aportes para una ecología política latinoamericana (pp. 2I-4I). Buenos Aires: CLACSO.

Machado, H. (2009). Auge minero y dominación neocolonial en América Latina. Ecología política de las transformaciones socioterritoriales neoliberales. XXVII Congreso de la Asociación Latinoamericana de Sociología. Buenos Aires: Asociación Latinoamericana de Sociología. Recuperado de: http://www.aacademica.com/000-062/I I07.pdf (20I0). “'El agua vale más que el oro'. Grito de resistencia descolonial contra los nuevos dispositivos expropiatorios", en G. C. Delgado Ramos (coord.), Ecología política de la minería en América Latina (pp. 59-96). México: UNAM y Centro de Investigaciones Interdisciplinarias de Ciencias y Humanidades.

(20I2). Naturaleza mineral. Una ecología política del colonialismo moderno (tesis doctoral inédita). Facultad de Humanidades, Universidad Nacional de Catamarca: Catamarca. 
Bibliografía
Martínez-Alier, J. (2003). Environmentalism of the Poor. A study of ecological conflicts and valuation. Reino Unido: Edward Elgar Publishing.

- y Jusmet, R. (200I). Economía ecológica y política ambiental. México: Fondo de Cultura Económica.

- y Schlüpmann, J. (I99I). La ecología y la economía. México: Fondo de Cultura Económica.

Massuh, G. (20I2). Renunciar al bien común. Extractivismo y (pos)desarrollo en América Latina. Buenos Aires: Mardulce.

(20/3). "Consenso de los commodities, giro ecoterritorial y pensamiento crítico latinoamericano". Revista del Observatorio Social de América Latina, (32). Recuperado de: http://maristellasvampa.net/archivos/ ensayo59.pdf

Merchand, M. (20I2). La globalización y el quehacer del Estado en la política económica y sectorial de México. México: $U$. de G.

(20I3). Acumulación por desposesión en la geografia glocal. México: Universidad de Guadalajara.

Molina, F. (20 de enero de 2016). "Las empresas chinas aumentan su poder de mercado en el mercado boliviano". El País. Recuperado de: http://economia.elpais.com/economia/20 I6/0 I/20/actualidad/I453328933_524034.html

OMAL (2015). Organización de Multinacionales de América Latina. Recuperado de: http://omal.info/spip. php?article5666\#direct4

Quijano, A. (1992). "Colonialidad y modernidad/racionalidad”, en H. Bonilla (comp.), Los conquistados: 1492 y la población indígena de las Américas (Pp. 437-449). Quito: FLACSO/Ediciones Libri Mundi.

(2004). "El laberinto de América Latina: ¿hay otras salidas?". Revista Venezolana de Economía y Ciencias Sociales, IO(I), 75-97. 
(2007). "Colonialidad del poder y clasificación Bibliografía social”, en S. Castro y Grosfoguel (ed.), El giro decolonial: reflexiones para una diversidad epistémica más allá del capitalismo global. Bogotá: Universidad Javeriana/ Universidad Central/Siglo del Hombre.

Sanborn, C., y Dammert, J. (2013). Extracción de recursos naturales, desarrollo económico e inclusión social. Perú: Centro de Investigación de la Universidad del Pacífico. Recuperado de: http://www.as-coa.org/sites/default/ files/MiningReportPeru20I3.pdf

Svampa, M. (2008). Cambio de época. Movimientos sociales y poder político. Buenos Aires: Siglo XXI.

(2012). "Pensar el desarrollo desde América Latina", en G. Massuh (comp.), La renuncia al bien común. Extractivismo y (post)desarrollo en América Latina (pp. 27-42). Buenos Aires: Mardulce.

- (20I3). "'Consenso de los commodities' y lenguajes de valoración en América Latina”. Revista Nueva sociedad, (244), 30-46.

- y Antonelli, M. (2009). Minería transnacional, narrativas del desarrollo y resistencias sociales. Buenos Aires: Biblos.

Schatan, J. (1998). Deuda externa y neoliberalismo: El saqueo de América Latina. Santiago de Chile: Fundación CENDA, Centro de Estudios Nacionales de Desarrollo Alternativo.

Toledo, V. (1980). "Ecología del modo campesino de producción”. Antropología y Marxismo, (3), 35-55.

(1990). "Modernidad y Ecología. La nueva crisis planetaria”. Ecología política, (3), 4I-78.

(1996). "Latinoamérica: crisis de civilización y ecología política”. Gaceta ecológica, (36), I3-22.

(2003). Ecología, espiritualidad y conocimiento. México: PNUMA/Universidad Iberoamericana. 
Bibliografía

Tudela, F. (2004). Los síndromes de sostenibilidad del desarrollo. El caso de México. Taller "Síndromes de sostenibilidad del desarrollo en América Latina". Serie. Seminario y conferencias 39. Santiago de Chile: División de Desarrollo Sostenible y Asentamientos Humanos, CEPAL.

UNASUR (20I3). Organización Latinoamericana de Energía -OLADE-. Potencial de recursos energéticos y minerales en América del Sur. Recuperado de: http://www.olade.org/ sites/default/files/publicaciones/Potencial-RecursosEnergeticos-Minerales-AS.pdf

Veltmeyer, H. (20I3). “Economía política de la extracción de recursos naturales ¿nuevo modelo de desarrollo o imperialismo extractitivo?". Estudios críticos del desarrollo, III(4). Recuperado de: https://issuu.com/comunicacionsocialuaz/docs/estudios-cr_ticos-4

Wallerstein, I. (2008). "Ecología y costes de producción capitalistas: no hay salida". Futuros, VI (20). Recuperado de: http://www.revistafuturos.info 